\section{The effect of the repeated presentation of a standard interval on the reproduction of the standard*}

\author{
TERRENCE MALONEY and ENOCH CALLAWAY \\ The Langley Porter Neuropsychiatric Institute, San Francisco, California 94122
}

Eleven human Ss (five male and six female) reproduced intervals of 1,2 , and 3 sec delimited by clicks after the standard intervals had been repeated one, three, or five times. The absolute error of reproduction decreased with increasing repetition of the standard for intervals of 2 and $3 \mathrm{sec}$. The effect was more pronounced with increasing duration among female Ss.

The study of the perception of time in humans has had many aspects. One of these is the duplication of intervals, called the method of reproduction. It has generally been assumed that only the immediately preceding interval affects the reproduction. The validity of this assumption is important not only in evaluating these studies, but in understanding the mechanisms underlying the perception of time. The present study was designed to determine the effects of repeating the standard interval on the reproduction of intervals of $3 \mathrm{sec}$ or less.

\section{METHOD}

The Ss were 11 paid volunteers from 20 to 32 years of age. There were five males and six females. The experiment was run under online control of a PDP-7 computer, which performed timing, recorded reproductions, and signaled changes in format. The intervals were delimited by clicks of less than $0.5 \mathrm{msec}$ duration. The clicks were delivered at a comfortable level through binaural earphones in a sound-attenuated room remote from the computer. The standard intervals and the Ss' responses were timed to the nearest millisecond.

The Ss were asked to reproduce intervals of 1,2 , or 3 sec after listening to five, three, or one standard intervals. There were no instructions given as to the method of timing, i.e., counting or tapping. A fully crossed and balanced design was used with 90 consecutive reproductions at each of the 1-,2-, and 3-sec intervals. These 90 reproductions consisted of three identical runs of 30 reproductions. The first 10

\footnotetext{
*This research is from the Langley Porter Neuropsychiatric Institute of the California Department of Mental Hygiene and from the Department of Psychiatry of the University of California Medical Center, San Francisco, and was supported by California Department of Mental Hygiene Grant 1-EXP, by National Institute of Mental Health General Research Support Grant FR05550, and by Office of Naval Research Contracts NONR 2931(00) and N00014-70-C-0248.
}

reproductions of a run were each made after a series of five intervals had been presented, the second 10 after three intervals, and the third 10 after one interval. Each run was followed by a 3-min rest.

The last click of each series of standard intervals generated by the computer was the signal for $S$ to begin his reproduction. $S$ signaled the end of his reproduction and triggered the final click of the series by pressing a microswitch on a small panel. Also on the panel were three lights, which indicated whether the first series (five intervals), second (three intervals), or third (one interval) was being presented. The appropriate light was on throughout the series. After $S$ had completed a reproduction, there was a 5 -sec wait, after which a fourth light on the panel flashed. $S$ would then press a switch to signal that he was ready. After a randomly selected interval of 0.5 to $2.0 \mathrm{sec}$ with 0.5 -sec increments following S's signal, the first click of the next series of standards would begin.

Each session consisted of 90 reproductions of $3 \mathrm{sec}$ intervals or 90 reproductions of 1 -sec intervals and 90 of 2 sec. The sequence of sessions was counterbalanced among $\mathrm{Ss}$, as was the sequence within sessions when 1- and 2 -sec intervals were used. The sessions in which 3-sec intervals were presented took under $45 \mathrm{~min}$, and the sessions in which 1- and 2-sec intervals were presented took less than $75 \mathrm{~min}$. The first two of the four sessions were

Table 1

Mean Absolute Error of Reproduction and Standard Deviations (in Seconds)

\begin{tabular}{llccc}
\hline & \multicolumn{3}{c}{ Number of Repetitions } \\
\cline { 2 - 4 } $\begin{array}{c}\text { Interval } \\
\text { Duration }\end{array}$ & 5 & 3 & 1 \\
\hline \multirow{2}{*}{ 1 Sec } & Mean & 0.068 & 0.068 & 0.068 \\
& SD & 0.068 & 0.068 & 0.069 \\
2 Sec & Mean & 0.089 & 0.108 & 0.121 \\
SD & 0.048 & 0.058 & 0.061 \\
3Sec & Mean & 0.153 & 0.166 & 0.212 \\
& SD & 0.051 & 0.055 & 0.071 \\
\hline
\end{tabular}

considered to be practice, and the data from them are not included in this study. Grossly apparent learning effects were observed only in the first session.

\section{RESULTS}

The first two reproductions of each series were excluded from the data. The remaining reproductions were transformed into absolute errors relative to the appropriate standard. An analysis of variance showed that variation among Ss was highly significant, as was duration of the standard interval (Table 1). The number of repetitions of the standard interval in a series was also significant and interacted significantly with $S$ and duration (Table 2). In general, the longer the interval, the greater the absolute error and the greater its reduction by repetition of the standard.

To characterize the variability among Ss further, an analysis of variance was performed on the data obtained from each S. For all Ss, both order and duration had highly significant effects. There was, however, no consistent pattern of the order effect from individual to individual and no obvious relation to variables not controlled in the experiment (i.e., time of day, $S$ fatigue). This is reflected in the subject-order term and nonsignificant order term for the group analysis of variance (Table 2 ). The number of repetitions of the standard was significant for five of the Ss at a level of 0.05 or less. There was an interaction between duration of the standard and number of repetitions for seven of the Ss significant at 0.05 or less. For three Ss, all male, neither number nor duration and number had a significant effect. Figure 1 illustrates the differences in mean absolute error between males and females. Sex and other personality factors have been cited as factors that affect the perception of time, although the reports are conflicting (Orme, 1969).

\section{DISCUSSION}

The effect of repeated intervals on the reproduction of an interval seems to have been studied only by Baker (1962). He found that after a series of intervals of varying duration, the Ss' reproductions were remarkably close to the mean duration of the series. This was in spite of the Ss' being instructed only to continue the series. The significant effects of duration and the number of replications in the present study are consistent with the suggestions that different mechanisms are employed for the discrimination of time, depending on the duration of the interval (Fraisse, 1964) and whether or not the interval is repeated (Michon, 1964). 
Table 2

Analysis of Variance of Absolute Error

\begin{tabular}{|c|c|c|c|}
\hline & $\mathbf{F}$ & $\mathbf{D F}$ & SIG \\
\hline Subject (S) & 75.82 & 10,2079 & .005 \\
\hline Duration (D) & 11.11 & 2,20 & .005 \\
\hline Order (O) & 1.76 & 2,20 & n.s. \\
\hline Number (N) & 5.82 & 2,20 & .025 \\
\hline$S$ by $D$ & 29.44 & 20,2079 & .005 \\
\hline$S$ by 0 & 5.43 & 20,2079 & .005 \\
\hline D by $O$ & 0.93 & 4,40 & n.s. \\
\hline $\mathrm{S}$ by $\mathbf{N}$ & 4.41 & 20,2079 & .005 \\
\hline D by $N$ & 2.95 & 4,40 & .05 \\
\hline O by $\mathbf{N}$ & 1.33 & 4,40 & n.s. \\
\hline$S$ by $D$ by $O$ & 4.03 & 40,2079 & .005 \\
\hline$S$ by $\mathrm{D}$ by $\mathrm{N}$ & 3.16 & 40,2079 & .005 \\
\hline$S$ by $O$ by $N$ & 1.72 & 40,2079 & .005 \\
\hline D by $O$ by $N$ & 1.08 & 8,80 & n.s. \\
\hline$S$ by $D$ by $O$ by $N$ & 1.66 & 80,2079 & .005 \\
\hline
\end{tabular}

Many of the studies using the method of reproduction have been concerned with the location of the indifference interval, that interval which is neither over- nor underestimated. This was not an area

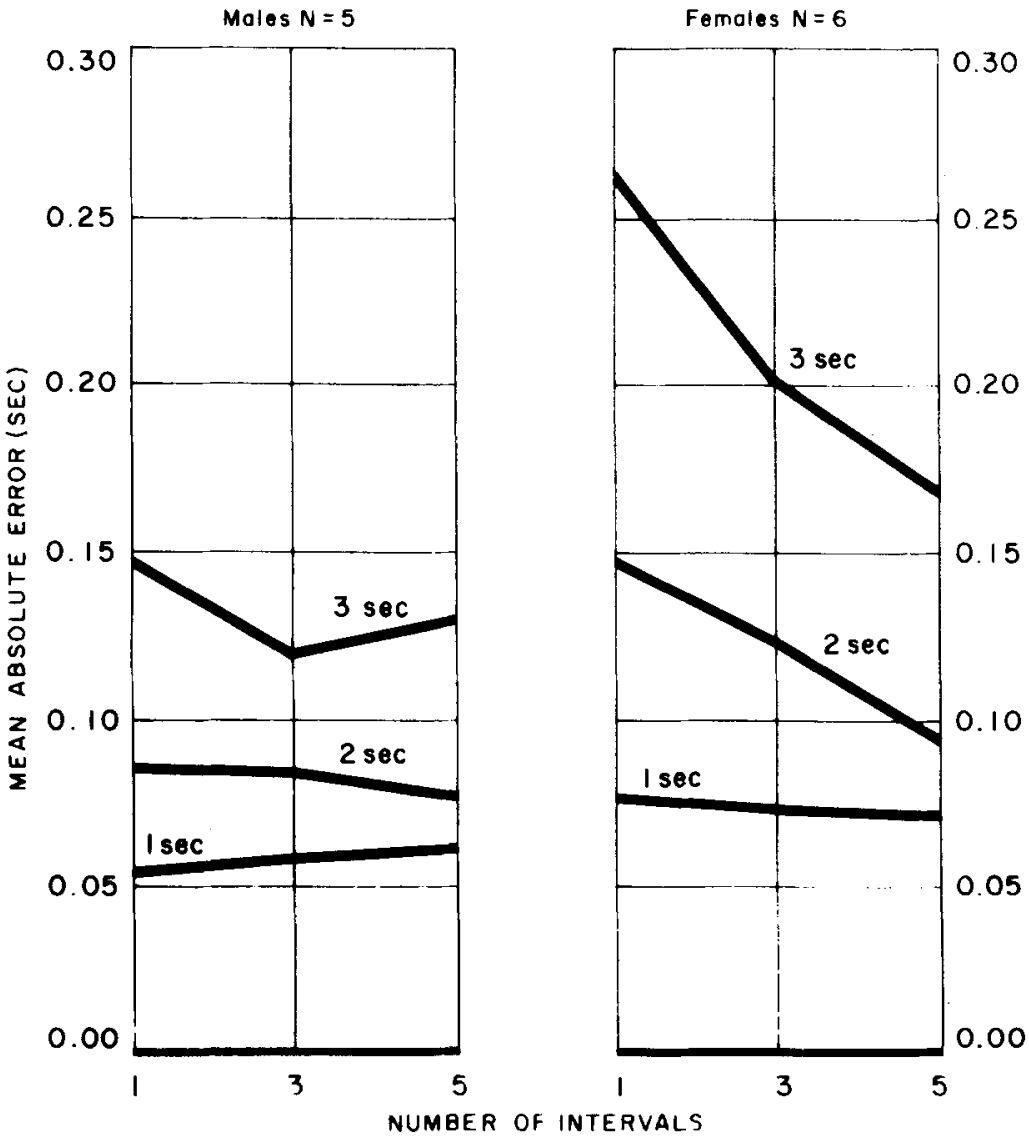

Fig. 1. Mean absolute error grouped by sex.
Table 3

Mean Relative Error of Reproduction and Standard Deviations (in Seconds)

\begin{tabular}{|c|c|c|c|c|}
\hline \multirow{2}{*}{\multicolumn{2}{|c|}{$\begin{array}{c}\text { Interval } \\
\text { Duration }\end{array}$}} & \multicolumn{3}{|c|}{ Number of $R$ epetitions } \\
\hline & & 5 & 3 & 1 \\
\hline $1 \mathrm{Sec}$ & $\begin{array}{l}\text { Mean } \\
\text { SI }\end{array}$ & $\begin{array}{r}+.021 \\
.053\end{array}$ & $\begin{array}{r}+.017 \\
.052\end{array}$ & $\begin{array}{r}+.001 \\
.063\end{array}$ \\
\hline $2 \mathrm{Sec}$ & $\begin{array}{l}M r a n \\
S_{L}\end{array}$ & $\begin{array}{r}-.015 \\
.092\end{array}$ & $\begin{array}{r}-.023 \\
.091\end{array}$ & $\begin{array}{r}-.038 \\
.110\end{array}$ \\
\hline $3 \mathrm{Sec}$ & $\begin{array}{l}M: \text { zan } \\
S D\end{array}$ & $\begin{array}{r}+.006 \\
.130\end{array}$ & $\begin{array}{r}+.008 \\
.135\end{array}$ & $\begin{array}{r}-.073 \\
.147\end{array}$ \\
\hline
\end{tabular}

of primary concern in this study, but the results are relevant to this question and warrant discussion. The data from this experiment, when recast so that over- and underestimations are reflected rather than absolute error, suggest that the effects of preceding intervals must be considered (Table 3). The few studies concerned with this in the past are conflicting. While Fox's (1952) study supports this, those of Du Preez (1967) and Kowalski (1943) do not. The conflicting reports arise, at least in part, from methodologies which are not entirely comparable.

In conclusion, the data presented here show a high degree of individual variability in the reproduction of intervals and indicate that the repetition of an interval decreases the absolute and relative error of reproduction for intervals of 2 and 3 sec. This effect becomes more prounounced with increasing duration and, in this study, was more pronounced among females.

\section{REFERENCES}

BAKER C. $H$ On temporal extrapolation. Canadian Journal of Psychology, 1962. $16,37-41$.

DU PREEZ, P. Reproduction of time intervals after short periods of delay. Journal of General Psychology, 1967, 76, 59-71.

FRAISSE, P. The prychology of time. New York: Harper and Row, 1964.

FOX, G. J. The effects of interval and duration of visual stimuli upon the time error. Psychological Newsletter, 1952, 45. 1-17.

KOWALSKI, W. The effect of delay upon the duplication of short temporal intervals. Journal of Experimental Psychology, 1943, 33, 239-246.

MICHON, T. A. Studies on subjective duration: I. Differential sensitivity in the perception of repeated temporal intervals. Acta Psychologica, 1964, 22, 441-450.

ORME, J. E. Time experience and behaviour. London: lliffe, 1969.

(Accepted for publication March 22, 1971.) 